\title{
TOTAL PARENTERAL NUTRITION
}

\author{
DR. TAHIR IQBAL MIRZA \\ MBBS, FCPS (Surgery) \\ PAC HOSPITAL KAMRA \\ DR. NAEEM SHAHID \\ MBBS, FCPS (Surgery) \\ PAC Hospital, Kamra
}

\author{
DR. MUHAMMAD ALI, \\ MBBS, FCPS (Surgery) \\ Combined Military Hospital, Gilgit \\ MBBS, FCPS, FRCS (Surgery) \\ Combined Military Hospital, Rawalpindi
}

\begin{abstract}
Objectives: Surgical patients often present with conditions that have either impaired ability to maintain their nutrition before operation or have made it impossible for them to obtain optimal nourishment by conventional means after surgical intervention. As rationing of the health care services became an increasing reality, the pressure to justify intervention such as nutrition support was intensified. The study was designed to see the indications, management and anticipated complications of total parentral nutrition in adult surgical patients. Design: Retrospective controlled study. Place and Duration of Study: During August 1997 to August 1998 at surgical department Pakistan Naval Ship (PNS) Hospital Shifa Karachi. Material and Methods: 30 indoor patients were selected. They were divided into three groups according to the pathological entities. After assessing nutritional status, providing emergency treatment of relative pathology and calculating calories, central line was maintained by approaching subclavian (76.6\%), femoral or antecubital vein. TPN was monitored, clinically and with laboratory investigations. Results: The group-I lagged approximately three days behind the others in achieving goal calories. Weight gain in most of the patients was significant after two weeks. Initially all three groups showed hyperglycemia, which was tapered by regular insulin over a Period of 3 to 3.5 days and rescheduling the nutrient substrates. Albumin did not change significantly. Catheter sepsis was evident in third group. Conclusion: It was concluded that Judicious use of TPN by thoughtful and conscientious nutritionist surgeons in surgical patients decreased morbidity/mortality rate, improved quality of life, with smooth recovery, convalescence and rehabilitation, decreased hospital stay and acceptable cost: benefit ratio.
\end{abstract}

Key words: $\quad$ Surgical patients, Malnutrition, Total Parentral nutrition, Complications, Better surgical results.

\section{INTRODUCTION}

Total parental nutrition ('Para' beside and 'entren' intestine) is the supply of highly concentrated nutrients in severely malnourished patients entirely through a large caliber vein over an extended period of time when gastrointestinal tract cannot be utilized for digestion and 
absorption purposes. It is instituted for a patient who has had nothing by mouth for 7 to 10 days and is anticipated that patient will not be able to maintain a normal state of nutrition through the usual entral route. It provides calories, proteins and essential fatty acids, as well as electrolytes, vitamins and trace elements sufficient to prevent a multitude of deficiency states. Malnutrition is assessed with help of physical parameters and laboratory investigations. Parentral nutritional support has under gone spectacularly great advancement and growth for the last few decades. Selection of the patients for this procedure entirely depends upon the degree of malnutrition and course of the disease. Implementation of the procedure is a teamwork it not only required the experiences of surgeon but also required the lending hand of a physician, nutritionist, and pharmacist and last but not the least TPN monitoring nurse.

The advantages of multidisciplinary team approach to nutritional support are decreased complication and cost saving for both hospital and patient ${ }^{5}$. Procedure is not complications free; they are traumatic, infectious or metabolic. Termination or shifting of the procedure from TPN to entral feeding is also experienced requiring job and transfer is a gradual process not a sudden turnover. Getting written consent and cost effectiveness are the hardship in Pakistan in gathering accurate data and availability of maximum number of the patients.

\section{MATERIAL \& METHOD}

Out of 30 indoor patients $70 \%$ were from Pakistan Defence Forces personnel and their dependants, where as $30 \%$ were from the civil population. The study conducted is neither of a specific group / place, nor represents any ethnic or geographic region. These patients were suffering from sever malnutrition due to underlying diseases, Group-l: carcinomas of oesophagus and stomach. Group-II: short bowel syndrome and high output upper gastrointestinal (GIT) fistulae. Group-III: with polytrauma, extensive burns and severe sepsis.
After reception at emergency and out door department, all patients were registered and their brief physical examination was carried out, then they were referred to their respective surgical units. The patients with extensive burns were directly shifted to the emergency operation theatre of PNS Hospital Shifa for primary resuscitation and calculation of burn area. After detailed discussion of cases by the surgical team with nutritionist and pharmacist the decision of TPN was made. Keeping in view the situation, the degree of malnutrition was calculated with careful physical examination and selectively requested laboratory tests and radiological examination. Anthropometrics measurements were noted like: -

$\begin{array}{ll}\text { - } & \text { Weight }(\mathrm{kg}) / \text { Height }(\mathrm{M})^{2} \text { index } \\ \text { - } & \text { Triceps skin folds in millimetres (TSF) } \\ \text { - } & \text { Mid arm circumference (MAC) in centimetres }\end{array}$

Catheters used were Hickman, Leonard and Broviac. They were Silicon made and radio-opaque. Percutaneous approach technique was used (Seldinger technique), out of 30 patients24 were selected for placement of catheter in the subclavian vein, four in femoral vein and two in ante-cubital vein. Caloric requirements were variable according to the severity of malnutrition ${ }^{2,3}$. Harris-Benedict Equation for basal energy expenditure (BEE) was used as per gender ${ }^{1}$ (Table-I).

Male $=66+13.7 \times$ Weight $(\mathrm{kg})+5 \times$ Height $(\mathrm{kg})-6.7 \mathrm{Age}(\mathrm{yrs})$ Female $=65.5+9.6 \times$ Weight $(\mathrm{kg})+1.7 \times$ Height $(\mathrm{cm})-4.7 \mathrm{Age}(\mathrm{yrs})$

All nutritional substrates and their dispensing services were provided by the pharmacy. For the monitoring of the procedure laboratory Investigations were requested from PNS Shifa Hospital, less levels of trace elements that were requested from Agha Khan Hospital Karachi (Table III).

Termination or move from TPN to oral or entral feeding was gradually done. The tips of the catheters were sent for bacteriological culture. 


\begin{tabular}{|l|c|c|c|c|}
\hline \multicolumn{2}{|c|}{ Table-1 Estimated values of caloric requirements and proteins in the studied patients (n=30) } \\
\hline Disease & \multicolumn{2}{|c|}{ Estimated Cal (K Cal/day) } & \multicolumn{2}{c|}{ Estimated proteins (g/day) } \\
\hline & Male & Female & Male & $132 \pm 18$ \\
\hline Ca Esophagus & $2941 \pm 50$ & $2658 \pm 30$ & $144 \pm 10$ & $122 \pm 8$ \\
\hline Ca stomach & $4308 \pm 90$ & $2890 \pm 20$ & $106 \pm 8$ & $126 \pm 10$ \\
\hline GIT fistulae & $2572 \pm 40$ & $2360 \pm 50$ & $96 \pm 12$ & $96 \pm 6$ \\
\hline S.B Syndrome & $2656 \pm 70$ & $2580 \pm 30$ & $178 \pm 8$ & $88 \pm 10$ \\
\hline Extensive burn & $4525 \pm 80$ & $3690 \pm 50$ & $128 \pm 10$ & $178 \pm 8$ \\
\hline Polytrauma & $295 \pm 50$ & - & - & - \\
\hline Severe sepsis & - & 2890 & & 104 \\
\hline
\end{tabular}

\begin{tabular}{|l|c|c|c|c|c|}
\hline \multicolumn{7}{|c|}{ Table-II Demographic data of patients at the time of entry into the study (n=30) } \\
\hline Disease & Male & Female & Age & Wt Range $(\mathrm{Kg})$ & Remarks \\
\hline Ca stomach & 3 & 2 & $42-60$ & $56-60$ & Lowest weight pts \\
\hline Ca oesophagus & 3 & 2 & $55-67$ & $69-72-5$ & The lowest albumin ratio \\
\hline GIT fistulae & 3 & 3 & $29-39$ & $64-66$ & All male pts \\
\hline SB syndrome & 4 & - & $27-35$ & $61.5-65.5$ & Max female pts \\
\hline Ext. Burn & 2 & 5 & $25-37$ & $64.5-66$ & Youngest pts \\
\hline Polytrauma & 2 & - & $25-27$ & $65-66$ & \\
\hline
\end{tabular}

\begin{tabular}{|l|l|}
\hline \multicolumn{2}{|c|}{ Table-Ill Investigations Requested for patients on TPN ( $\mathbf{n}=30)$} \\
\hline Form of investigations & Laboratory test \\
\hline Hematology & Blood complete examination \\
\hline Blood chemistry & $\begin{array}{l}\text { Sodium, potassium, magnesium, chloride, Bicarbonate, calcium, blood ureas nitrogen, creatinine, } \\
\text { phosphorus, zinc. Glucose and osmolarity }\end{array}$ \\
\hline Visceral protein & Transferrin and albumin \\
\hline $\begin{array}{l}\text { Finger/urine stick } \\
\text { measurements }\end{array}$ & Blood glucose level, Urine sugar/acetone \\
\hline Lipids & Triglyceride \\
\hline Coagulation profile & Prothrombin time \\
\hline Urine & 24 hours urine collection (for nitrogen balance), creatinine, Electrolytes (sodium and potassium) \\
\hline Bacteriology & Blood culture, skin puncture site, catheter tin \\
\hline
\end{tabular}




\section{RESULTS}

Out of 30 indoor patients evaluated, 17 were male and 13 were female. Among all three groups, patients in Group-I were the oldest, whereas in Group-III were the youngest (Table-1). Two patients who at early days refused for TPN and left the hospital by enjoying their right of refusal of medical treatment, later on rejoined the study after one and two days respectively. The study took longer duration than anticipated, in addition to problem of patients' compliance and difficulty in written consent.

Malnutrition was variable from severe catabolic state of short duration to chronic course of the disease. Group-I patients suffered chronic weight loss and were in cachexic state for the last two to four months with the lowest TSF and MAC measurements. Two of $\mathrm{Ca}$. Oesophagus patients were exposed to radiotherapy. In Group-II, patients had the shortest duration of weight loss (last 10 to 12 days) and main reason of malnutrition was under caloric diet. Albumin ratio was 2.79 - 3.00 $\mathrm{gm} / \mathrm{dL}$ in these patients at the start of study. All these patients were already surgically intervened and two patients were having coarse basal crepitations chest (bilateral). In group-III among burns patients, three were having more than $92 \%$ of burnt surface area (Two females and one male). This was the youngest group with highest mortality rate (30\%).

Two to three days of hospitalization were spent in management of emergency situations and neither group received enough calories. At this stage it was a great concern as to whether all these patients would respond to TPN enough to achieve the required goal nutritional calories.

Group-I patients lagged behind about 72 hours to gain acceptable feeding goal calories. Group-III patients gained their required goal feeding calories within 72 hours (Figure-1). Minimum weight gain was seen at fourteen days, in group-I patients $(<1 \mathrm{~kg})$. Progressive weight gain was seen in group-III and group-II respectively (Figure-2).

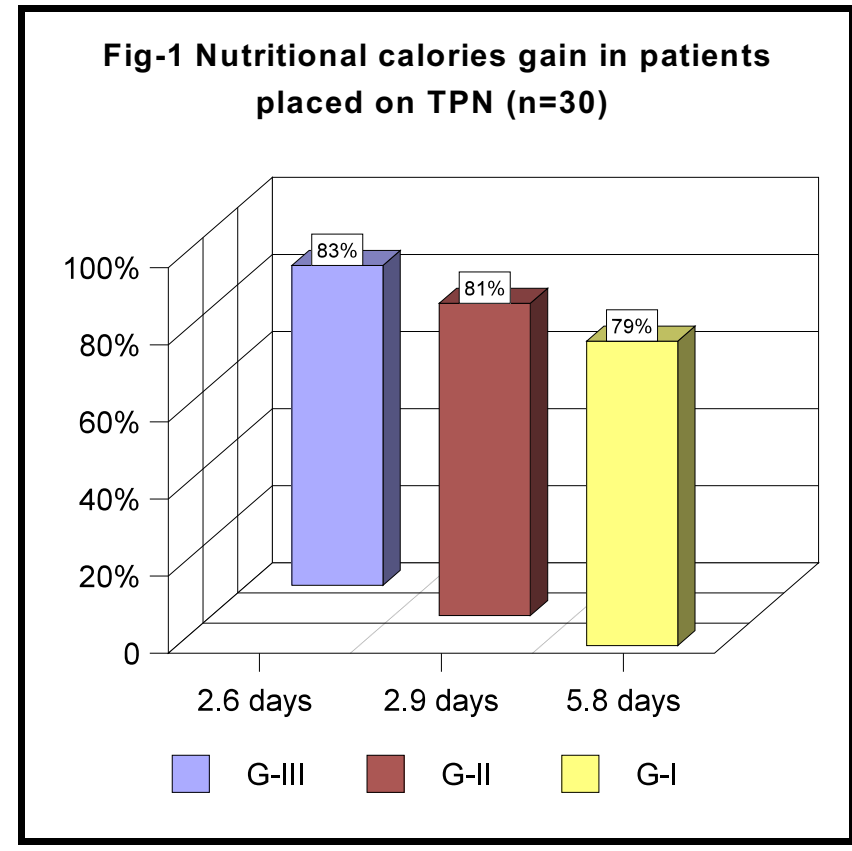

Fig-2 Serial weight gain in patients placed on TPN $(n=30)$

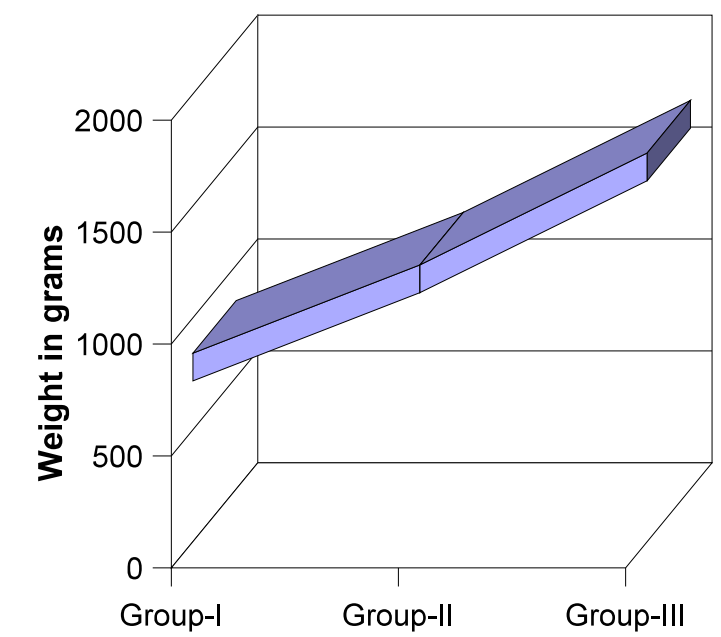

At the start of study blood glucose levels were checked randomly. The levels in group-I were $139-157 \mathrm{mg} / \mathrm{dL}$ (mean 148mg/dL), group-II was 127-130smg/dL (mean $128 \mathrm{mg} / \mathrm{dL}$ ) and group-III was $131-156 \mathrm{mg} / \mathrm{dL}$ (mean $143 \mathrm{mg} / \mathrm{dL}$ ). After hypertonic glucose infusions the mean concentration of glucose was quiet high in case of groupI and group-|II patients $161 \mathrm{mg} / \mathrm{dL}$ and $157 \mathrm{mg} / \mathrm{dL}$ respectively, which was later on tapered to smaller doses 
and decreased numbers of infusions (Figure-3). Initially regular insulin at the dose of $0.024-0.048 \mathrm{Unit} / \mathrm{gram}$ of dextrose was started, in all the three groups. In group-II and group-III it was stopped till 84 hours, while in group-I it was extended for another 48 hours due to persistent hyperglycemia. It was also observed that insulin administration in case of fistulae patients resulted in hypoglycemia. No significant change was observed in the concentration of plasma albumin at fourteenth day, of the procedure.

Fig-3 Blood sugar levels in studied patients at the time of entry in study and after 48 hours of TPN

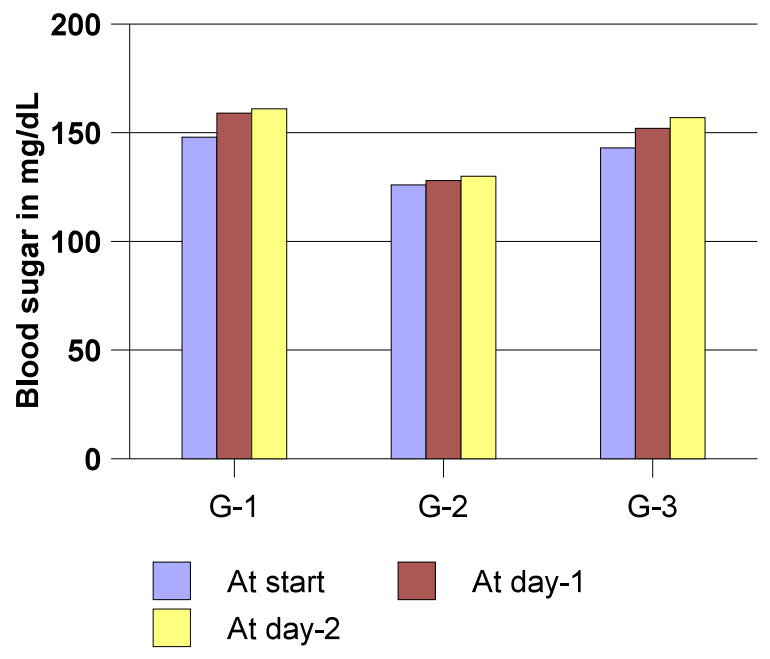

Catheters remained for longer duration with out complication in group-I (mean24.5days) followed by group-II (mean 21.6days) and group-III (mean18.6days) respectively. The tips of the removed catheters were sent for microbial culture. They were found positive for Staphylococcus aureus $4.1 \%, 8.2 \%$ and $12.3 \%$ for group I, II and respectively. Average expenditure per day for group-III was the maximum (mean3500+150 Pak Rupee), where as for group-II moderates (2900 \pm 100 Pak

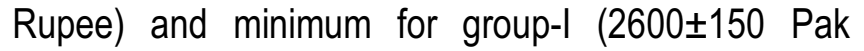
Rupee).

\section{DISCUSSION}

Specific challenge to the nutritional support is that it is most often ancillary, especially for indoor patients. Majority of the patients who require active nutritional support undergo this experience secondary to a condition that has lead to nutritional disorders such as diminished intake of nutrients, altered metabolism of nutrients or malabsorption of nutrients. In an era of rationing of health care services, secondary support modalities become immediate targets for reduction of ailment ${ }^{2}$. While initiation of any critically proposed treatment as well as during TPN administration, following three criteria must be fulfilled ${ }^{4}$.

- With convincing evidences that treatment is effective in improving health outcomes comparing no treatment.

- With comparison of no treatment, its beneficial effects should outweigh any harmful effects on health outcomes.

- Compared with the next best possible alternative, regimen should represent a good use of available sources.

Thus it is the responsibility of the nutritional support specialists to justify the use of nutritional support. A major obstacle to the justification of this intervention is the existence of complications associated with its delivery. The indication of TPN has been focused considerably as study has shown that well nourished patients should not undergo TPN under normal circumstances. Limitation of case study is due to the fact that large numbers of subjects are not available for the randomized study at individual centers for TPN5. Another limitation of the randomized study in this field is that outcome differences are often dependent on clinical entities rather than nutritional support. Although the methods are in a continued phase of evolution yet the protocol cannot be altered once the study has begun.

The results are directly being affected with the adaptation of TPN in those surgically ill patients where supply of diet is compromised due to severity or nature of the disease. It is worth mentioning that the procedure 
success lies in the basic understanding of patient selection, nutrition, biochemistry, anatomy pathphysiology, pharmacology, advanced surgical technology and epidemiology.
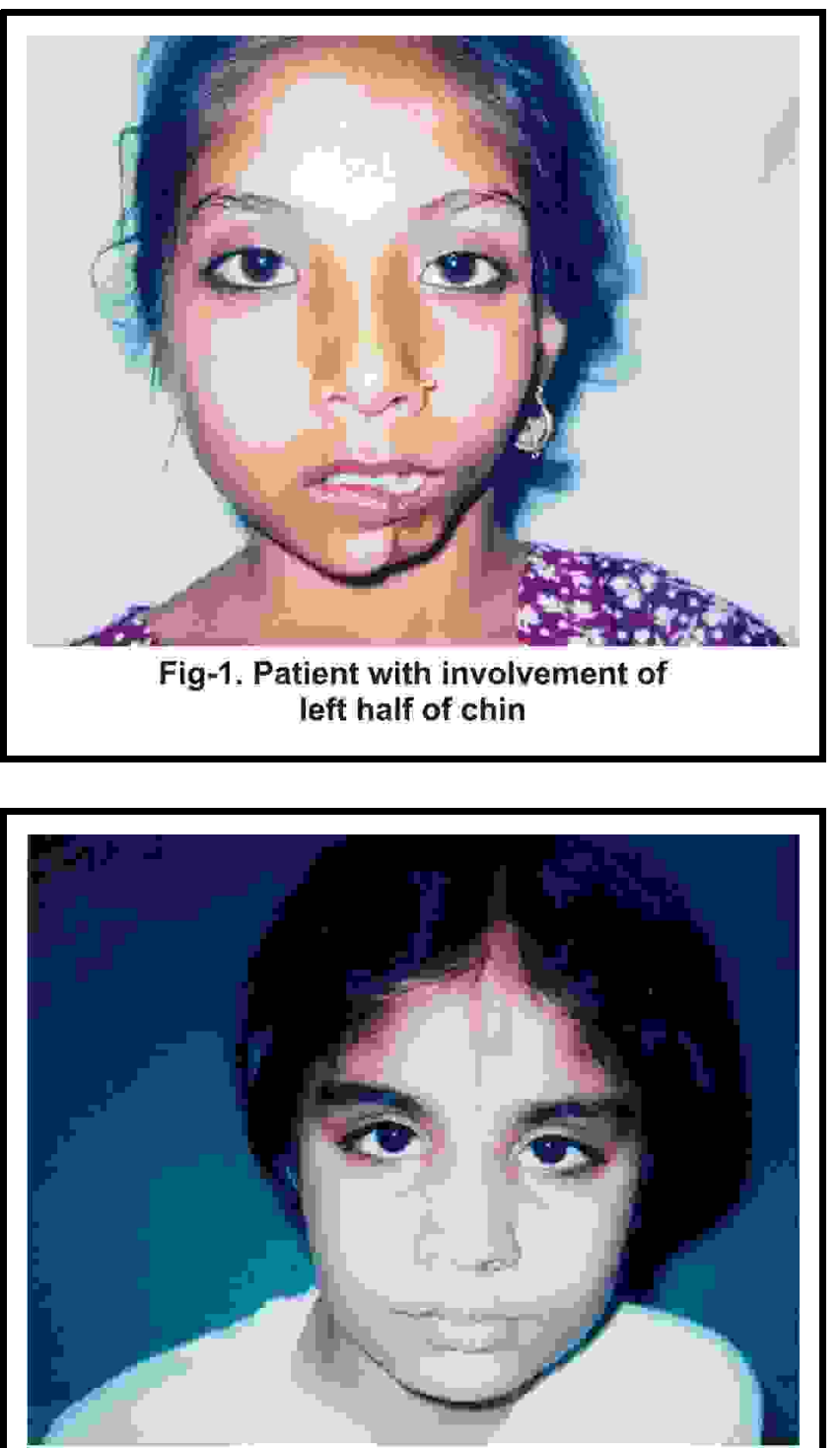

Fig-2. Disease starting in midline and effecting left half forehead.

It is suggested that the wide spread use of TPN might not be warranted ${ }^{5}$ and it is now becoming apparent that a multidisciplinary approach team with collaboration of skilled medical personnel and well trained nutritional support team is the mainstay of the procedure's success.
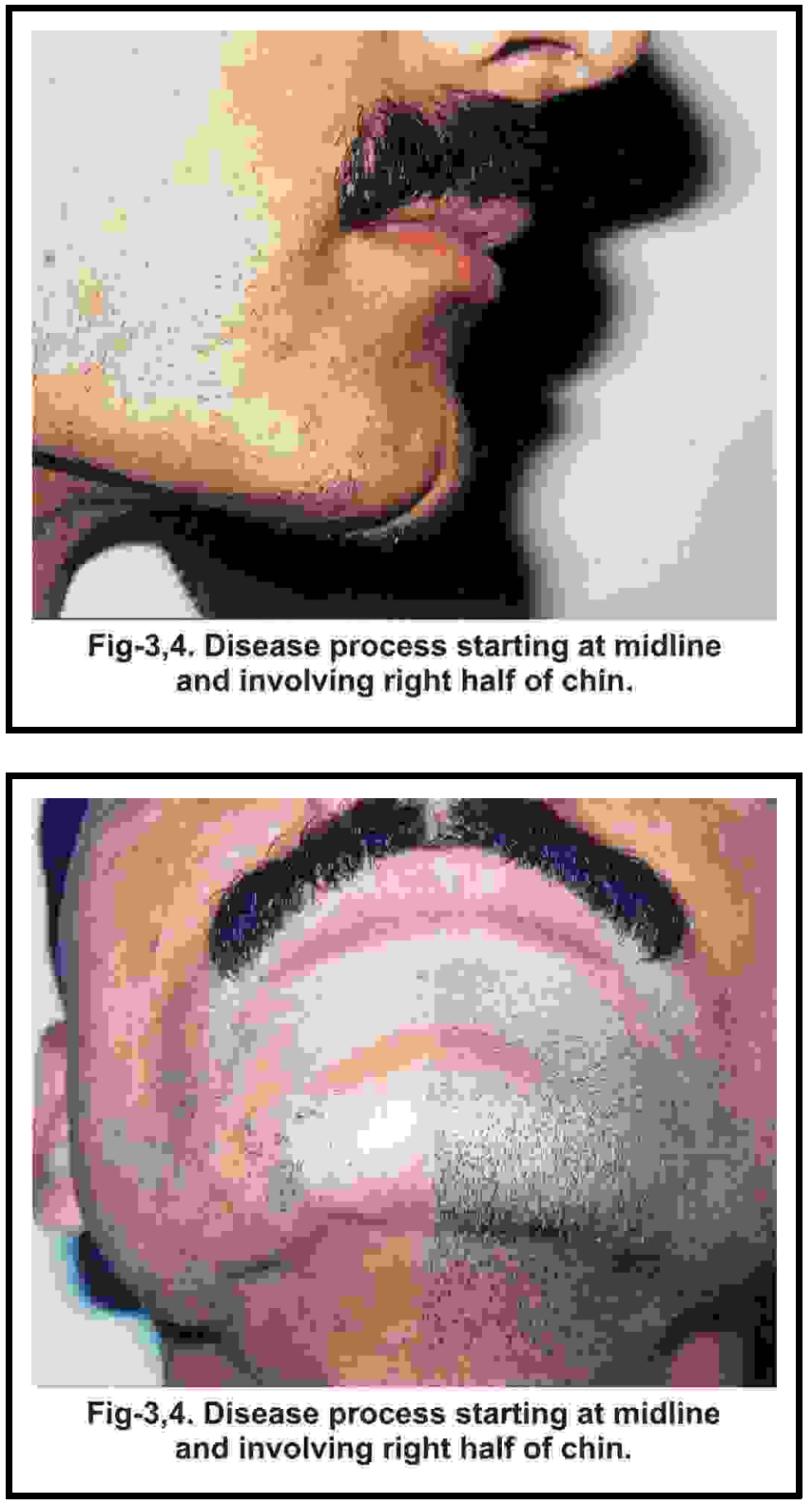

Png and $\mathrm{Ong}^{6}$ in their study found that with formation of Surgical Nutrition Advisory team, there was decline of catheter sepsis from $35.1 \%$ to $15.4 \%$, and a wise selection of patients resulted in less metabolic complications. Less than 3-4 \% of all hospital admissions underwent the procedure ${ }^{2}$. Reported malnutrition incidences ranged from 10 to $50 \%$ in different series of hospitalized patients ${ }^{6}$. In 1979 Mullen et al viewed that accurate judgment of request for laboratory test is also mandatory ${ }^{7}$. However besides conventional laboratory 
tests, test like transferrin, thyroxin binding prealbumin ${ }^{6}$, retinol binding protein, somatomedin-c, fibrinogen ,haptoglobin, C-reactive protein and fibronectin have been suggested as possible markers of the nutritional status measurements ${ }^{8}$.

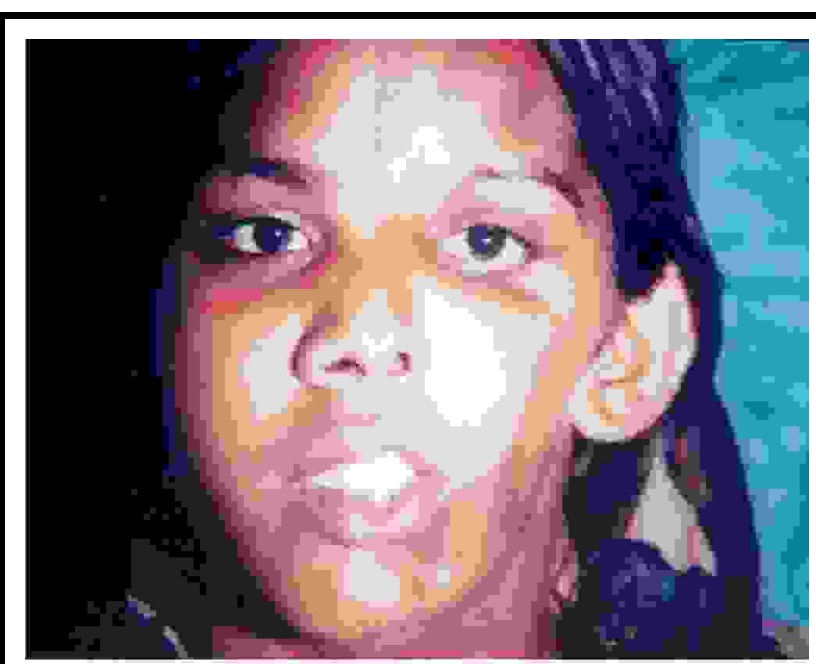

Fig-5, Involvement of left half of face

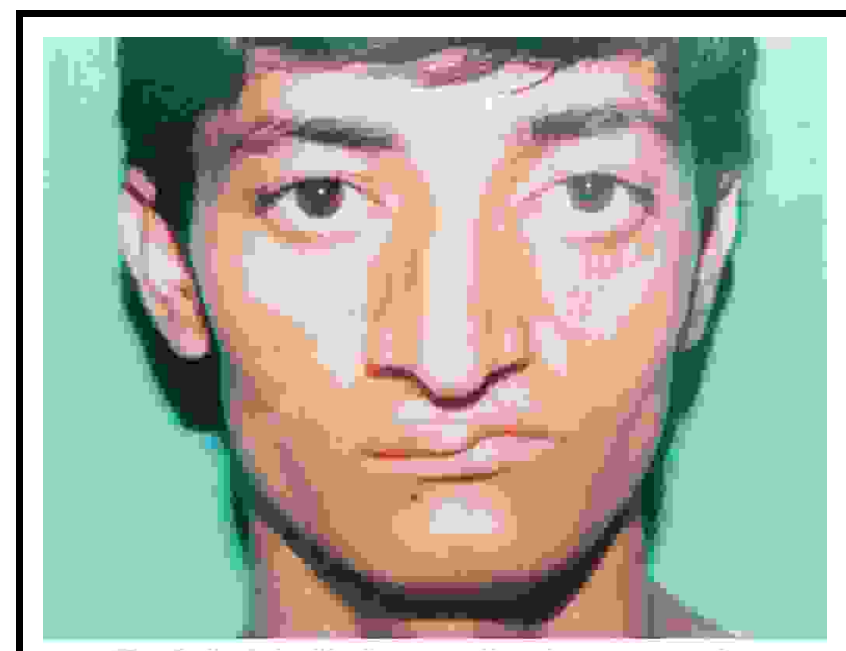

Fig-6. Left half of upper lip shows atrophy.

Group-I patient lagged behind the other groups for achieving the caloric goal (Figure-1). On fourth day, which was the third day of TPN, maximum feedings were received by group-III. In 1997 in a comparison study by Stephen it was observed that the time taken for management of emergencies was of concern in the patients who showed delay in achieving the caloric goal and it was maximum in patients with acute pancreatitis who were on TPN?

After fourteen days of close monitoring it was observed that minor weight gain was achieved in group-l, which was less than a $\mathrm{Kg}$ (Figure-2). Weight gain was progressive among the second and third group. Our results are in accordance with the results of Bozzetti and associates in year 1998. In a study of 90 patients who were given TPN, it was seen that there was improvement in weight loss percentage (From base line of 18.2 to $16.2 \%$ ) after a ten days TPN preoperatively. The results were conditional with the adequate fluid and calories adjustments, with weight loss not more than $10 \%{ }^{10}$. Our study results also coincide with Fischer and Holter ${ }^{11}$ conclusion in year 1977 which narrated that the patients with $10 \%$ body weight loss of their ideal body weight for the last two months showed a gain $(n=30)$ in these patients with compare to those who did not receive TPN $(n=26)$ and with another group of patients who were not having a significant weight loss ( $\mathrm{n}=28$ ). But in contrary, a study by Russell and associates ${ }^{12}$ in year 1984 noticed that in patients of small cell carcinoma who were with advanced stage tumor and metabolic derangements did not show a favorable response to TPN. Also supporting our finding, DeWys and colleagues in 1980, in a study of more than 3000 cancer patients found the better survival rates in those patients who did not lose weight, compared with those patients who lost more than $6 \%$ of their body weight ${ }^{13}$. Likewise in 1977 Holter found same findings during his study, of hyperalimentation ${ }^{11}$.

The albumin levels were found to be lowest in the first group with a range $2.5-3.00 \mathrm{gm} / \mathrm{dL}$ and mean $2.7 \mathrm{gm} / \mathrm{dLs}$, with compared to other groups. At the end of fourteen days there was no significant change in the albumin levels in all three groups (mean for group-III, $2.8 \mathrm{gm} / \mathrm{dL}$ ). Supporting our findings Llyd and associates ${ }^{14}$ in 1991 reached to the conclusion that the levels of albumin cannot test any acute change in the nutritional status as it possesses a long half life (About 18 days). Similarly Rubin and associates in 1997 found in their study that 
supplementation of the albumin in TPN solution could not change the morbidity or mortality and albumin is relatively insensitive marker of the early malnutrition or recovery following refeeding ${ }^{15}$. Likewise, in other study TPN started immediately after surgery could not counteract the obligatory decline of muscles protein synthesis and albumin observed 24 hours postoperatively $^{16}$. Likely Greenblatt declared in his study in 1976 that albumin less than $2.2 \mathrm{gm} / \mathrm{dL}$ indicated a sever malnutrition ${ }^{17}$. Differing with our findings, Reinharted and associates demonstrated a correlation between the degree of hypoalbuminemia and 30 day mortality in the hospitalized patients ${ }^{16}$.

The levels of glucose were mildly raised in the patients of group-I (mean $148 \mathrm{mg} / \mathrm{dL}$ ) at the start of the study. After 12 to 24 hours of TPN, there was increase in the random serum levels of glucose in group-I and the group-III, with mean $161 \mathrm{mg} / \mathrm{dL}$ and $157 \mathrm{mg} / \mathrm{dL}$ respectively. Likely Schein ${ }^{18}$ and Lundholm ${ }^{19}$ in year 1979 in two different sets of the studies in severely malnourished patients of the cancer observed that with the infusion of glucose in these subjects an early rise of glucose was observed that was due to the metabolic derangement and presence of tumor. With exogenous insulin (regular) the levels were tapered down within 72-84 hours and then the regular insulin was withdrawn. In group-II patients a mild raise was tapered with adjustment of the nutrients concentration. Our findings also coincided with the results of Stephen and associates ${ }^{9}$ study of patients with malnutrition in 1996 due to acute pancreatitis $(n=32)$, they discovered that those patients who received TPN $(n=16)$ were hyperglycemic compared with those who were not given TPN $(n=16)$. Similarly Schloerb in 1998 studied 107 patients ${ }^{21}$ and found hyperglycemia in one fourth of American academic centers, where he suggested a $15 \%$ dextrose formula at a rate of not more than $4 \mathrm{mg} /$ minute. This has also been ascertained by a study by Stwart and Blackburn ${ }^{20}$ that glucose calories are to be delivered at approximately $4 \mathrm{mg} / \mathrm{kg} /$ minutes to avoid hyperglycemia. Favouring our findings $\mathrm{MacFie}^{22}$ and Bozzetti ${ }^{23}$ reached at a conclusion that TPN itself could lead to early hyperglycemia.
The subclavian vein $(76.6 \%$ of the total patients) was the site of the choice. Maximum stay of catheter was noted with a mean period of 24.5 days in group-I, and minimum with group-III with mean 18.5 day. Maximum incidences of catheter sepsis were recorded in group-III, especially in burn patients (12.3\%). Yeung and associates in 1998 found after the study ${ }^{24}$ of 378 patients by designed for determination of efficacy of the central venous catheter compared with the peripheral catheter it was seen that the Subclavian vein was with less sepsis rates, he also concluded that longer the duration of TPN, higher the complication rate, including catheter sepsis With the agreement of our finding Png and Ong in their study in1997 suggested that a better selection of patients is also much essential for less completions like catheter sepsis ${ }^{6}$. Likewise Bozzetti et al selected in subclavian vein in maximum patients for catheterization and it was with less percentage of sepsis ${ }^{10}$. But pleading against the results, Robertson and associates in 1990 concluded that in exhausted patients, catheter could be placed in IVC through transhepatic or translumber approach, in those cases where superior vena cava thrombosis is evident ${ }^{23}$. Cost effectiveness was another factor starting from the catheters to the solutions and their additives with the burden of investigations and other hospital resources. In our study, expenses were born by the state for all entitled personnel, and for civilian patients it was approximately $3100 \pm 250$ for a single day in Pakistani rupee. In a study by Kotler and colleagues it was evident that cost effectiveness was four times more than oral or semi $\operatorname{diet}^{25}$.

\section{CONCLUSION}

Malnutrition is recognized as one of the factor affecting surgical patient morbidity and mortality. Malnutrition is an added risk for altered wound or anastomatic healing. Judicial decision to start TPN should not be delayed. Conventional methods including visceral protein measurements, anthropometrics measurements and energy skin testing. Unfortunately, are neither solely altered by nutritional status nor can they accurately predict risk to the individual patient. 


\section{REFERENCES}

1. John M, Dely Redmond HP and Michael D Lieberman et al: Current strategies in surgical nutrition. The Surgical Clinics of North America1991;71: 523-536.

2. Truswell AS, Baird JD.In Davidson's Principles and Practice of Medicine Published by Livingston at London :Nutritional factors in disease.1991;16th Ed:45-79.

3. Russell RCG, Williams NS and Bulstrode CJK. In Bailey \& love Short practice of surgery. Published by Arnold at London Nutritional support and rehabilitation 2000; 23rd Ed: 64-73.

4. $\quad$ Eddy D M: Health system reform, will controlling costs require rationing services? JAMA1994;272:324-328.

5. Nehme A.E., et al: Nutritional support of the hospitalized patients. J.AMA1980; 243:1906-1908.

6. Peng D J, Ong C L, Chan $S$ et al: Surgical Nutritional Team \& its impact on TPN : Int $J$ Clint.Pract1997;51(6):350-352.

7. Mullen JL., Gertner M H, Buzby G P et al: Implications of malnutrition in surgical patients. Arch surg1979; 114:121-125.

8. Heymsfield SB, Willum PJ : Nutritional assessment by clinical and biochemical methods in shils,ME, Young VR Ed: Modern Nutrition in health and disease. Philadelphia, Lea and Febiger1988; 817- 850.

9. Stephen A, McClave et al: Comparison of the Safety of Early Entral vs Parenteral Nutrition. JPEN1997;21:1419.

10. Bozzetti F, Gavazzi C, Meiceli R , Rossi N, Mariani L et al: Perioperative TPN in malnourished GIT cancer patients: A randomized clinical trial.JPEN1989;24(1):7-13.

11. Fischer JE, Holterm AR et al: The effects of perioperative hyper alimentation on complications in patients with cancer and weight loss. J.Surg Res1977;23:31-34.

12. Russeel D, Shieke M, Marliss E et al: Effects of TPN and chemotherapy on metabolic derangements in small cell lung cancer. Cancer res 1984;44:1706-1711.

13. DeWys W.D., Begg C, Lavin PT et al: Prognostic effects of weight loss prior to chemotherapy in cancer patients. AmJ Med1980;69:491- 497.

14. Lloyd C, Smith MD, James $L$ et al: Nutritional assessment and indications for nutritional support. Surg Clin of North Am1991;73(3):449-457.

15. Rubin H, Garlson S, Demeo M, Ganger D, Craig RM et al: Randomized, double-binding study of Intravenous human albumin in hypoalbuminenmic patients receiving TPN.Crit.care, Med1997;25(2):249-252.

16. Reinherdt GF,MyscofskiRD. WilkensD et al: Incidence and mortality of hypoalbuminemic patients in hospitalized veterans. JPEN.1982:4:357-59.

17. Greenblatt DJ, Ransil BJ, Ha rmanta JS et al: Variability of 24 hours urine creatinine excretion by normal subjects. J.Clin. Pharamacol1976; 16:321-328.

18. Schein PS, Kisner D, Haller D et al: Cachexia of malignancy : Potential role of insulin in institutional management. Cancer1976; 49:2070-2076.

19. Lundholm K, Edsrom S, Karlberg I et al: Insulin resistance in patients with progressive malignant disease. Cancer Res 1979; 39:1968-1972.

20. Stwart R.K., Blackburn GL: Nutritional support in surgical patients. In Camron JL (Ed): Current surgical therapy, Ed3.Toronto, BC Deeker11989; p776.

21. Schloerb PR, Henning JF et al: Pattern and problems of adult TPN use in US Academic Medical centers. Arch Surg 1998;133:7-12.

22. Mac Fie J, Smith RC, Hill GH et al: Glucose or fat as a non protein energy source? A Controlled trial in GIT patients, requiring intravenous nutrition Gastroenterology1981; 80:103-107.

23. Bozzetti F, Ammatuna S et al : Comparison of glucose vs. Glucose fat sol. In cancers patients: Controlled crossover stydy.Clint.Nutr1990;9:325-330.

24. Yeung $C Y$, Lee H C, Hang F Y, Wang CS: Sepsis during TPN: Exploration of risk factors and determination of effectiveness of peripherally inserted central venous catheter. Pediatric infect dis J1998;17(2): 135-142.

25. Kotler DP, Fogleman L, Tierney A R et al: Comparison of TPN, Oral and semi elemental diet on body composition, physical function and nutritional related costs in patients with malabsorption due to AIDS. JPEN1997; 22:120-126. 
